Published in final edited form as:

Am J Prev Med. 2016 October ; 51(4): 502-506. doi:10.1016/j.amepre.2016.07.003.

\title{
Ideal Cardiovascular Health and Incident Cardiovascular Events:
}

The Jackson Heart Study

Mark J. Ommerborn, MPH ${ }^{1}$, Chad T. Blackshear, MS $^{2}$, DeMarc A. Hickson, PhD, MPH $^{3,4}$, Michael E. Griswold, PhD², Japneet Kwatra, MSc, BDS ${ }^{1}$, Luc Djousse, MD, ScD, MPH ${ }^{5,6,7,8}$, and Cheryl R. Clark, MD, ScD ${ }^{1,7,9}$

${ }^{1}$ Center for Community Health and Health Equity, Brigham and Women's Hospital, Boston, Massachusetts

${ }^{2}$ Center of Biostatistics and Bioinformatics, University of Mississippi Medical Center, Jackson, Mississippi

${ }^{3}$ Center for Research, Evaluation and Environmental and Policy Change, My Brother's Keeper, Inc., Jackson, Mississippi

${ }^{4}$ Department of Epidemiology and Biostatistics, Jackson State University, Jackson, Mississippi

${ }^{5}$ Department of Medicine, Brigham and Women's Hospital, Boston, Massachusetts

${ }^{6}$ Division of Aging, Brigham and Women's Hospital, Boston, Massachusetts

${ }^{7}$ Harvard Medical School, Boston, Massachusetts

${ }^{8}$ Boston VA Healthcare System, Boston, Massachusetts

${ }^{9}$ Division of General Medicine and Primary Care, Brigham and Women's Faulkner Hospitalist Program, Boston, Massachusetts

\section{Abstract}

Introduction-The epidemiology of American Heart Association ideal cardiovascular health $(\mathrm{CVH})$ metrics has not been fully examined in African Americans. This study examines associations of CVH metrics with incident cardiovascular disease (CVD) in the Jackson Heart Study, a longitudinal cohort study of CVD in African Americans.

Methods-Jackson Heart Study participants without CVD $(\mathrm{N}=4,702)$ were followed prospectively between 2000 and 2011. Incidence rates and Cox proportional hazard ratios estimated risks for incident CVD (myocardial infarction, stroke, cardiac procedures, and CVD mortality) associated with seven CVH metrics by sex. Analyses were performed in 2015.

Address correspondence to: Cheryl R. Clark, MD, ScD, Center for Community Health and Health Equity, Brigham and Women's Hospital, 1620 Tremont Street, Boston MA 02120. crclark@partners.org.

No financial disclosures were reported by the authors of this paper.

Publisher's Disclaimer: This is a PDF file of an unedited manuscript that has been accepted for publication. As a service to our customers we are providing this early version of the manuscript. The manuscript will undergo copyediting, typesetting, and review of the resulting proof before it is published in its final citable form. Please note that during the production process errors may be discovered which could affect the content, and all legal disclaimers that apply to the journal pertain. 
Results-Participants were followed for a median 8.3 years; none had ideal health on all seven CVH metrics. The prevalence of ideal health was low for nutrition, physical activity, BMI, and blood pressure metrics. The age-adjusted CVD incidence rate (IR) per 1,000 person years was highest for individuals with the least ideal health metrics: zero to one (IR=12.5, 95\% CI=9.7, 16.1), two ( $I R=8.2,95 \% \mathrm{CI}=6.5,10.4)$, three ( $\mathrm{IR}=5.7,95 \% \mathrm{CI}=4.2,7.6)$, and four or more ( $\mathrm{IR}=3.4,95 \% \mathrm{CI}=2.0,5.9)$. Adjusting for covariates, individuals with four or more ideal CVH metrics had lower risks of incident CVD compared with those with zero or one ideal CVH metric (hazard ratio, 0.29; 95\% $\mathrm{CI}=0.17,0.52 ; p<0.001$ ).

Conclusions-African Americans with more ideal CVH metrics have lower risks of incident CVD. Comprehensive preventive behavioral and clinical supports should be intensified to improve CVD risk for African Americans with few ideal CVH metrics.

\section{Introduction}

Substantial racial and ethnic disparities in cardiovascular disease (CVD) prevalence, incidence, and mortality exist, with African Americans experiencing the highest disease burden. ${ }^{1}$ In 2010, the American Heart Association (AHA) developed metrics for assessing seven modifiable health behaviors and physiologic biomarkers for the purpose of improving cardiovascular health $(\mathrm{CVH}){ }^{2}$ These metrics rate $\mathrm{CVH}$ as ideal, intermediate, or poor based on clinical cut offs within the seven identified risk factors (smoking, BMI, physical activity, diet, blood pressure, total cholesterol, and fasting glucose). ${ }^{2}$ A previous analysis reported low prevalence of AHA CVH in the Jackson Heart Study (JHS). ${ }^{3}$ Several multiethnic cohorts have examined AHA CVH prevalence and associated incident CVD by race. ${ }^{4-7}$ The Northern Manhattan Study (NOMAS), Atherosclerosis Risk in Communities Study (ARIC), and Reasons for Geographic and Racial Difference in Stroke cohorts found increased CVD and stroke risk associated with a lower number of ideal $\mathrm{CVH}$ risk factors among African American participants. ${ }^{5-7}$ The relation between AHA CVH and incident CVD has not been examined in the JHS, the largest single-site, prospective epidemiologic cohort of African Americans in the U.S. The JHS was developed to examine the etiology of CVD among African Americans who have a high prevalence of cardiovascular risk factors. The current study examined the longitudinal association between the number of ideal CVH metrics and incident CVD events in African Americans in the JHS cohort.

\section{Methods}

\section{Population and Study Design}

The JHS is an observational cohort study of 5,301 individuals in the Jackson, Mississippi metropolitan area. Detailed study design methods have been described previously. ${ }^{8,9}$ Briefly, participants were recruited from: volunteers who were representative of the Jackson metropolitan area African American population in terms of age, sex, and socioeconomic characteristics; participants of the ARIC study; and adult family members of initial JHS study participants. ${ }^{8}$ 
The JHS study was approved by Jackson State University, Tougaloo College, and the University of Mississippi Medical Center IRBs, and all participants provided informed consent. These analyses were approved by the Partners HealthCare IRB.

This analysis included data from the first clinical examination and survey (2000-2004) through 2011. Median follow up was 8.3 years. Five hundred ninety-nine individuals with a history of coronary heart disease, stroke, or both prior to study entry were excluded, for a final cohort of 4,702 .

\section{Measures}

Methods for classifying CVD events in the JHS evolved from the ARIC study and have been published. ${ }^{10-12}$ Incident CVD was classified as a first event of fatal or non-fatal myocardial infarction, coronary heart disease, cardiac procedure, or stroke. Person years at risk for cardiovascular events were calculated from the date of the first exam to the date of a fatal or non-fatal CVD event, a fatal non-CVD event, or until the end of the current follow-up period, December 31, 2011. All measures were captured during the first exam via previously described procedures. ${ }^{13-16}$ The seven AHA CVH metrics were classified as ideal, intermediate, or poor health (Appendix A). ${ }^{2}$ Covariates included self-reported age, sex, education, and annual family income scaled for family size. ${ }^{17-19}$

\section{Statistical Analysis}

Cox proportional hazard models were used to estimate incident CVD hazard ratios (HRs) associated with the number of ideal cardiovascular health metrics (zero to one, two, three, or four or more metrics), adjusted for age, sex, income, and education. Data were also analyzed by sex to investigate potential sex differences between $\mathrm{CVH}$ metrics and incident cardiovascular events. ${ }^{20-25}$ Participants with diabetes did not fast for laboratory tests, resulting in missing data on cholesterol and glucose. To prevent bias arising from missing data, multiple imputation techniques were used. ${ }^{26,27}$ Online Appendices B and C provide additional information on these analyses. All analyses were conducted in SAS, version 9.3 in 2015 .

\section{Results}

Of the 4,702 studied individuals, $292 \mathrm{had}$ an incident CVD event. Among the 4,410 individuals who did not have a CVD event, 315 died from non-CVD related conditions and were censored at time of death.

Most participants (83.0\%) had three or fewer ideal health metrics and no participants had ideal health on all CVH metrics (Appendix D). Participants with more ideal CVH metrics were younger, and had higher incomes and education. Men and women did not differ in the distribution of ideal CVH metrics (Table 1).

There was an inverse relationship between the number of ideal health metrics and ageadjusted CVD incidence rates ( $p$-value for trend $<0.001$, Figure 1 ). 
There was a linear inverse association between the risk of CVD events and the number of ideal health metrics in fully adjusted models ( $p$-value for trend $<0.001$, Table 2 ). Compared with those with zero or one ideal health metric, those with two ( $\mathrm{HR}=0.66,95 \% \mathrm{CI}=0.49$, $0.88)$, three $(\mathrm{HR}=0.45,95 \% \mathrm{CI}=0.32,0.64)$, or four or more $(\mathrm{HR}=0.29,95 \% \mathrm{CI}=0.17,0.52)$ ideal health metrics had lower risk of CVD events. Similar associations were observed for women.

Sensitivity analyses excluding individuals with missing data showed similar results for both the non-imputed and imputed models (Appendix C).

\section{Discussion}

This prospective cohort study of African Americans in Jackson, Mississippi found an inverse, graded association between the number of ideal health metrics and incident CVD. The CVD incidence rate was highest for individuals with zero or one ideal health metric.

The JHS CVD incidence rates were lower than those among African Americans in the ARIC and NOMAS cohorts. This may be because the definition of incident CVD events used in this analysis did not capture heart failure events as were included in the ARIC and NOMAS rate calculation. ${ }^{7,8}$

This study found a similar inverse relationship between the number of ideal health metrics and risk of CVD events as seen among African Americans in the NOMAS and ARIC studies. ${ }^{7,8}$ The extremely low prevalence of ideal $\mathrm{CVH}$ and the close association with incident CVD in the JHS cohort provide context to understand the high burden of CVD observed in the South. ${ }^{28}$ These data support the urgent need for interventions to promote better management of $\mathrm{CVH}$ risk factors for African Americans. Evidence-based interventions designed to target hypertension, hyperlipidemia, tobacco use, diet, and physical activity include culturally tailored lifestyle interventions involving nutrition counseling, exercise, sodium restriction, stress reduction, and smoking cessation. ${ }^{29-31}$ Successful interventions include community-level interventions that use multicomponent, multidisciplinary teams of healthcare professionals, patients, and community members. ${ }^{31}$ Additional research is needed to determine strategies for addressing multiple risk contributors for CVD for high-risk groups.

There are numerous strengths to this study, including its prospective study design, large sample, and robust measures of CVD events, CVH metrics, and potential confounders.

\section{Limitations}

To reduce potential bias from missing data, multiple imputation methods were used. The authors acknowledge the potential bias when estimating complete missing data for people with diabetes; yet, sensitivity analyses showed results with non-imputed data were not substantially different from imputed data. The JHS used validated methods of CVD event ascertainment, but it cannot fully account for events that do not present clinically (e.g., silent myocardial infarction). 


\section{Conclusions}

The findings underscore the critical importance of comprehensive prevention approaches to address metrics of $\mathrm{CVH}$ to protect the cardiovascular health of African Americans in Jackson, Mississippi. Going forward, a key goal for population health is to shift the distribution of $\mathrm{CVH}$ metrics toward lower risk profiles for these groups.

\section{Supplementary Material}

Refer to Web version on PubMed Central for supplementary material.

\section{Acknowledgments}

The authors wish to acknowledge the kind advice and assistance of Ms. Kaitlyn Moran and Ms. Wanda McClain, of the Center for Community Health and Health Equity at Brigham and Women's Hospital.

This research was supported with funding from the National Institutes of Aging (K08 AG 032357). The Jackson Heart Study was supported by the National Heart, Lung, and Blood Institute and the National Center for Minority Health and Health Disparities (contracts N01-HC-95170, N01-HC-95171, and N01-HC-95172). The funders had no role in study design, data collection and analysis, decision to publish, or preparation of the manuscript.

\section{References}

1. Mozaffarian D, Benjamin EJ, Go AS, et al. on behalf of the American Heart Association Statistics Committee and Stroke Statistics Subcommittee. Heart disease and stroke statistics-2016 update: a report from the American Heart Association. Circulation. 2016; 133(4):e38-e360. http://dx.doi.org/ 10.1161/CIR.0000000000000350. [PubMed: 26673558]

2. Lloyd-Jones DM, Hong Y, Labarthe D, et al. American Heart Association Strategic Planning Task Force and Statistics Committee. Defining and setting national goals for cardiovascular health promotion and disease reduction: the American Heart Association's strategic Impact Goal through 2020 and beyond. Circulation. 2010; 121(4):586-613. http://dx.doi.org/10.1161/ CIRCULATIONAHA.109.192703. [PubMed: 20089546]

3. Djoussé L, Petrone AB, Blackshear C, et al. Prevalence and changes over time of ideal cardiovascular health metrics among African-Americans: The Jackson Heart Study. Prev Med. 2015; 74:111-116. http://dx.doi.org/10.1016/j.ypmed.2015.02.006. [PubMed: 25712326]

4. Miao C, Bao M, Xing A, et al. Cardiovascular Health Score and the Risk of Cardiovascular Diseases. PLoS One. 2015; 10(7):e0131537. http://dx.doi.org/10.1371/journal.pone.0131537. [PubMed: 26154254]

5. Kulshreshtha A, Vaccarino V, Judd SE, et al. Life's Simple 7 and risk of incident stroke: the reasons for geographic and racial differences in stroke study. Stroke. 2013; 44(7):1909-1914. http:// dx.doi.org/10.1161/STROKEAHA.111.000352. [PubMed: 23743971]

6. Dong C, Rundek T, Wright CB, et al. Ideal cardiovascular health predicts lower risks of myocardial infarction, stroke, and vascular death across whites, blacks, and Hispanics: the northern Manhattan study. Circulation. 2012; 125(24):2975-2984. http://dx.doi.org/10.1161/CIRCULATIONAHA. 111.081083. [PubMed: 22619283]

7. Folsom AR, Yatsuya H, Nettleton JA, et al. Community prevalence of ideal cardiovascular health, by the American Heart Association definition, and relationship with cardiovascular disease incidence. J Am Coll Cardiol. 2011; 57(16):1690-1696. http://dx.doi.org/10.1016/j.jacc.2010.11.041. [PubMed: 21492767]

8. Fuqua SR, Wyatt SB, Andrew ME, et al. Recruiting African-American research participation in the Jackson Heart Study: Methods, response rates, and sample description. Ethn Dis. 2005; 15(4 Suppl 6):18-29. 
9. Taylor H, Liu J, Wilson G, et al. Distinct component profiles and high risk among African Americans with metabolic syndrome: the Jackson Heart Study. Diabetes Care. 2008; 31(6):12481253. http://dx.doi.org/10.2337/dc07-1810. [PubMed: 18332154]

10. Keku E, Rosamond W, Taylor HA Jr, et al. Cardiovascular disease event classification in the Jackson Heart Study: methods and procedures. Ethn Dis. 2005; 15(4 Suppl 6):62-70.

11. White AD, Folsom AR, Chambless LE, et al. Community surveillance of coronary heart disease in the Atherosclerosis Risk in Communities (ARIC) study: methods and initial two years' experience. J Clin Epidemiol. 1996; 49(2):223-233. http://dx.doi.org/10.1016/0895-4356(95)00041-0. [PubMed: 8606324]

12. Rosamond WD, Folsom AR, Chambless LE, et al. Stroke incidence and survival among middleaged adults: 9-year follow-up of the Atherosclerosis Risk in Communities (ARIC) cohort. Stroke. 1999; 30(4):736-743. http://dx.doi.org/10.1161/01.STR.30.4.736. [PubMed: 10187871]

13. Tucker KL, Maras J, Champagne C, et al. A regional food-frequency questionnaire for the U.S. Mississippi Delta. Public Health Nutr. 2005; 8(1):87-96. http://dx.doi.org/10.1079/PHN2005663. [PubMed: 15705249]

14. Carithers TC, Talegawkar SA, Rowser ML, et al. Validity and calibration of food frequency questionnaires used with African-American adults in the Jackson Heart Study. J Am Diet Assoc. 2009; 109(7):1184-1193. http://dx.doi.org/10.1016/j.jada.2009.04.005. [PubMed: 19559135]

15. Bell EJ, Lutsey PL, Windham BG, Folsom AR. Physical Activity and cardiovascular disease in African Americans in Atherosclerosis Risk in Communities. Med Sci Sports Exerc. 2013; 45(5): 901-907. http://dx.doi.org/10.1249/MSS.0b013e31827d87ec. [PubMed: 23247714]

16. Carpenter MA, Crow R, Steffes M, et al. Laboratory, reading center, and coordinating center data management methods in the Jackson Heart Study. Am J Med Sci. 2004; 328(3):131-144. http:// dx.doi.org/10.1097/00000441-200409000-00001. [PubMed: 15367870]

17. Rehkopf DH, Krieger N, Coull B, Berkman LF. Biologic risk markers for coronary heart disease: nonlinear associations with income. Epidemiology. 2010; 21(1):38-46. http://dx.doi.org/10.1097/ EDE.0b013e3181c30b89. [PubMed: 20010209]

18. Parker RN, Fenwick R. The Pareto Curve and Its Utility for Open-Ended Income Distributions in Survey Research. Soc Forces. 1983; 61(3):872-885. http://dx.doi.org/10.1093/sf/61.3.872.

19. Clark CR, Ommerborn MJ, Hickson DA, et al. Neighborhood disadvantage, neighborhood safety and cardiometabolic risk factors in African Americans: biosocial associations in the Jackson Heart Study. PLOS One. 2013; 8(5):e63254. http://dx.doi.org/10.1371/journal.pone.0063254. [PubMed: 23691005]

20. Johnson, PA.; Fitzgerald, T.; Salganicoff, A.; Wood, SF.; Goldstein, JM. Sex-Specific Medical Research: Why Women's Health Can't Wait. Brigham and Women's Hospital; 2014. http:// www.brighamandwomens.org/Departments_and_Services/womenshealth/ConnorsCenter/Policy/ ConnorsReportFINAL.pdf [Accessed May 24, 2016]

21. DeVon HA, Ryan CJ, Ochs AL, Shapiro M. Symptoms across the Continuum of Acute Coronary Syndromes: Differences between Women and Men. Am J Crit Care. 2008; 17(1):14-25. [PubMed: 18158385]

22. Arslanian-Engoren C, Patel A, Fang J, et al. Symptoms of Men and Women Presenting with Acute Coronary Syndromes. Am J Cardiol. 2006; 98:1177-1181. http://dx.doi.org/10.1016/j.amjcard. 2006.05.049. [PubMed: 17056322]

23. Kudenchuk PJ, Maynard C, Martin JS, Wirkus M, Weaver WD. Comparison of Presentation, Treatment, and Outcome of Acute Myocardial Infarction in Men versus Women. Am J Cardiol. 1996; 78:9-14. http://dx.doi.org/10.1016/S0002-9149(96)00218-4.

24. Kimble LP, McGuire DB, Dunbar SB, et al. Gender Difference in Pain Characteristics of Chronic Stable Angina and Perceived Physical Limitation in Patients with Coronary Artery Disease. Pain. 2003; 101(0):45-53. http://dx.doi.org/10.1016/S0304-3959(02)00319-6. [PubMed: 12507699]

25. Zucker DR, Griffith JL, Beshansky JR, Selker HP. Presentations of Acute Myocardial Infarction in Men and Women. J Gen Intern Med. 1997; 12:79-87. http://dx.doi.org/10.1007/ s11606-006-5001-0. [PubMed: 9051556]

26. Rubin DB. Multiple imputation after 18+ years. J Am Statist Assoc. 1996; 91:473-489. http:// dx.doi.org/10.1080/01621459.1996.10476908. 
27. Schafer, IL. Analysis of incomplete multivariate data. 72. London: Chapman \& Hall; 1997. http:// dx.doi.org/10.1201/9781439821862

28. Caspar M, Kramer MR, Quick H, et al. Changes in the Geographic Patterns of Heart Disease Mortality in the United States 1973 to 2010. Circulation. 2016; 133:1171-1180. http://dx.doi.org/ 10.1161/CIRCULATIONAHA.115.018663. [PubMed: 27002081]

29. Davis AM, Vinci LM, Okwuosa TM, Chase AR, Huang ES. Cardiovascular health disparities: A systematic review of health care interventions. Med Care Res Rev. 2007; 64(Suppl 5):29S-100S. http://dx.doi.org/10.1177/1077558707305416. [PubMed: 17881625]

30. Crook ED, Bryan NB, Hanks R, et al. A review of interventions to reduce health disparities in cardiovascular disease in African Americans. Ethn Dis. 2009; 19(2):204-208. [PubMed: 19537234]

31. Stuart-Shor EM, Berra KA, Kamau MW, Kumanyika SK. Behavioral strategies for cardiovascular risk reduction in diverse and underserved racial/ethnic groups. Circulation. 2012; 125(1):171-184. http://dx.doi.org/10.1161/CIRCULATIONAHA.110.968495. [PubMed: 22215892] 

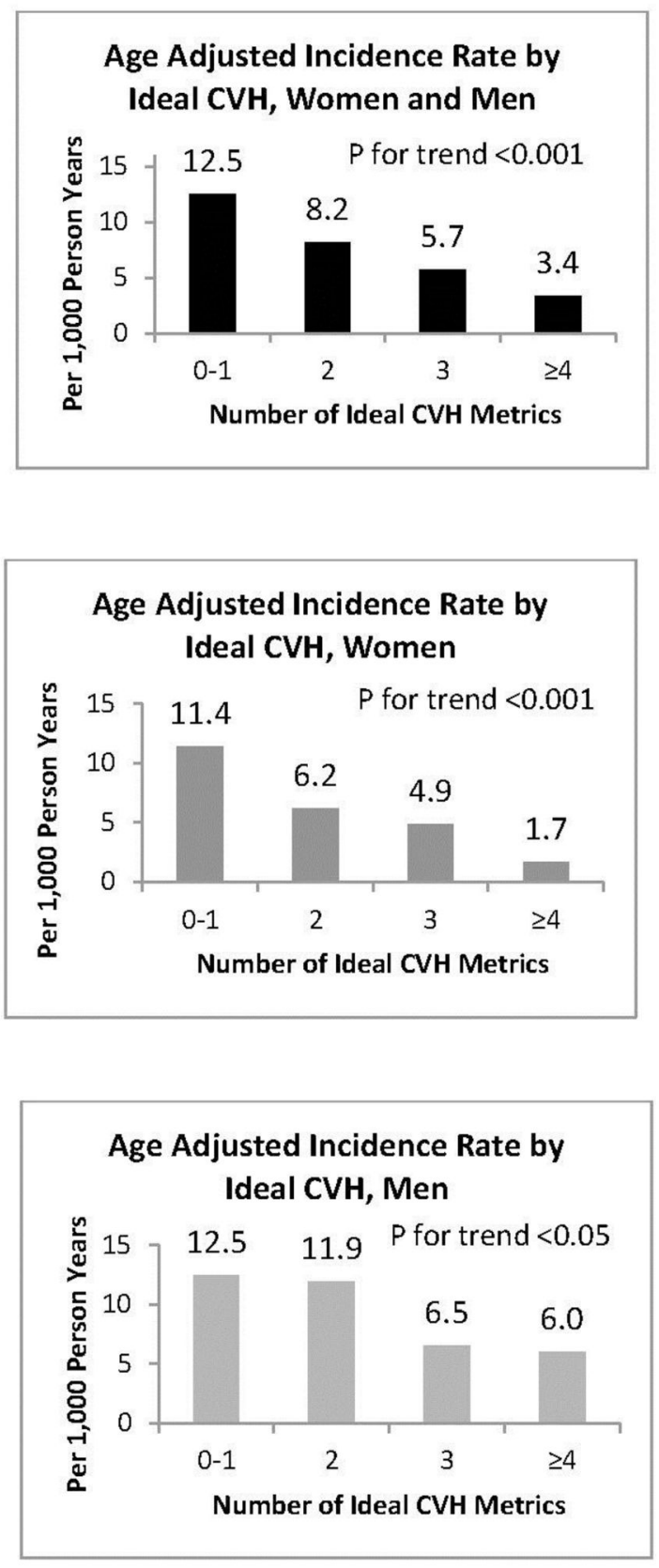

Figure 1.

Incidence rates for cardiovascular disease events by number of ideal cardiovascular health metrics by sex, the Jackson Heart Study.

Notes: Cardiovascular disease incidence rates calculated via PROC GENMOD in SAS. The incidence rates are calculated per 1,000 person-years. $\mathrm{CVH}$, cardiovascular health 


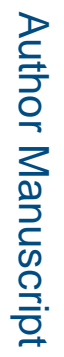

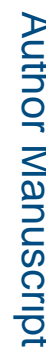

I
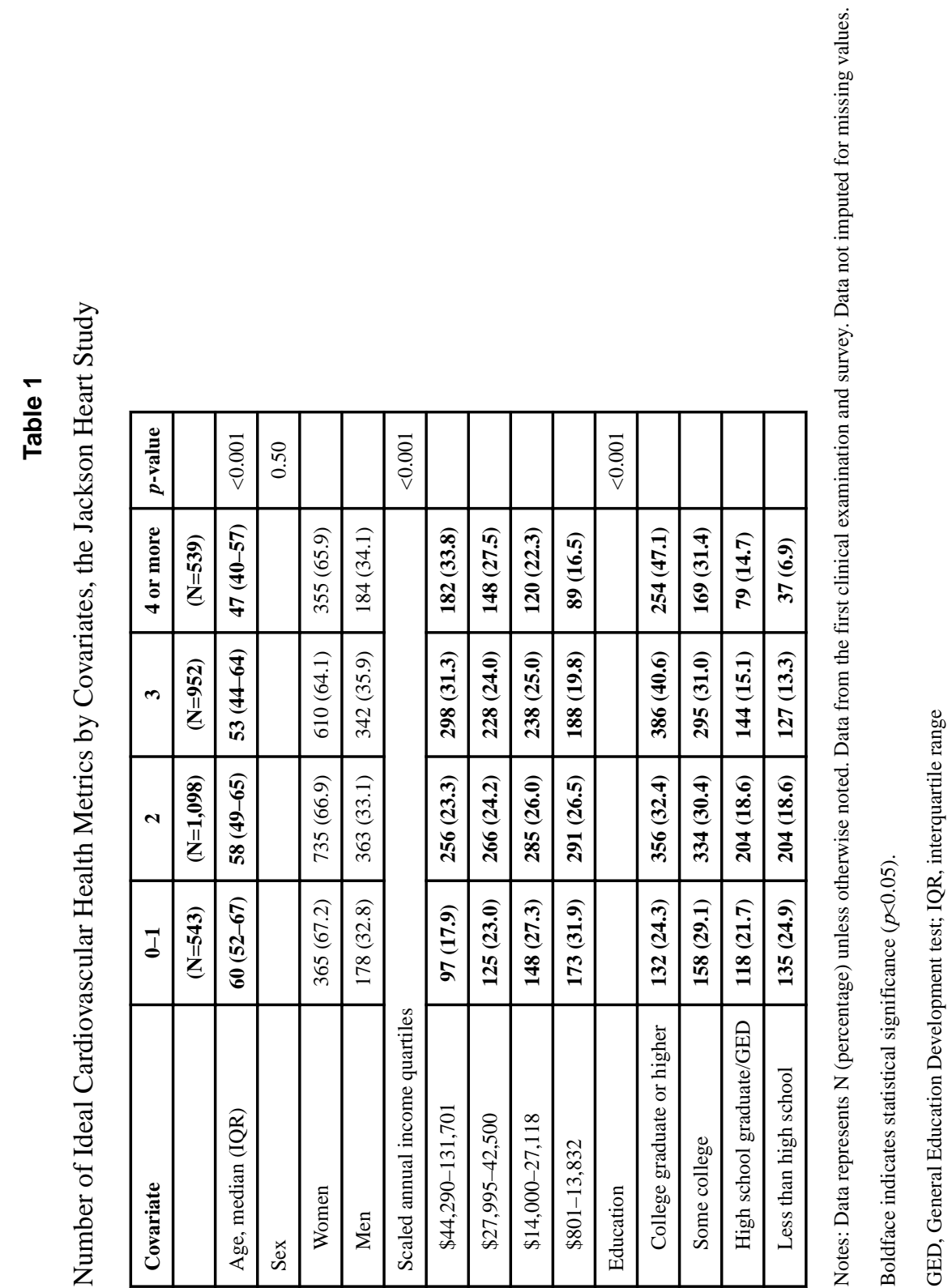

Am J Prev Med. Author manuscript; available in PMC 2017 October 01. 


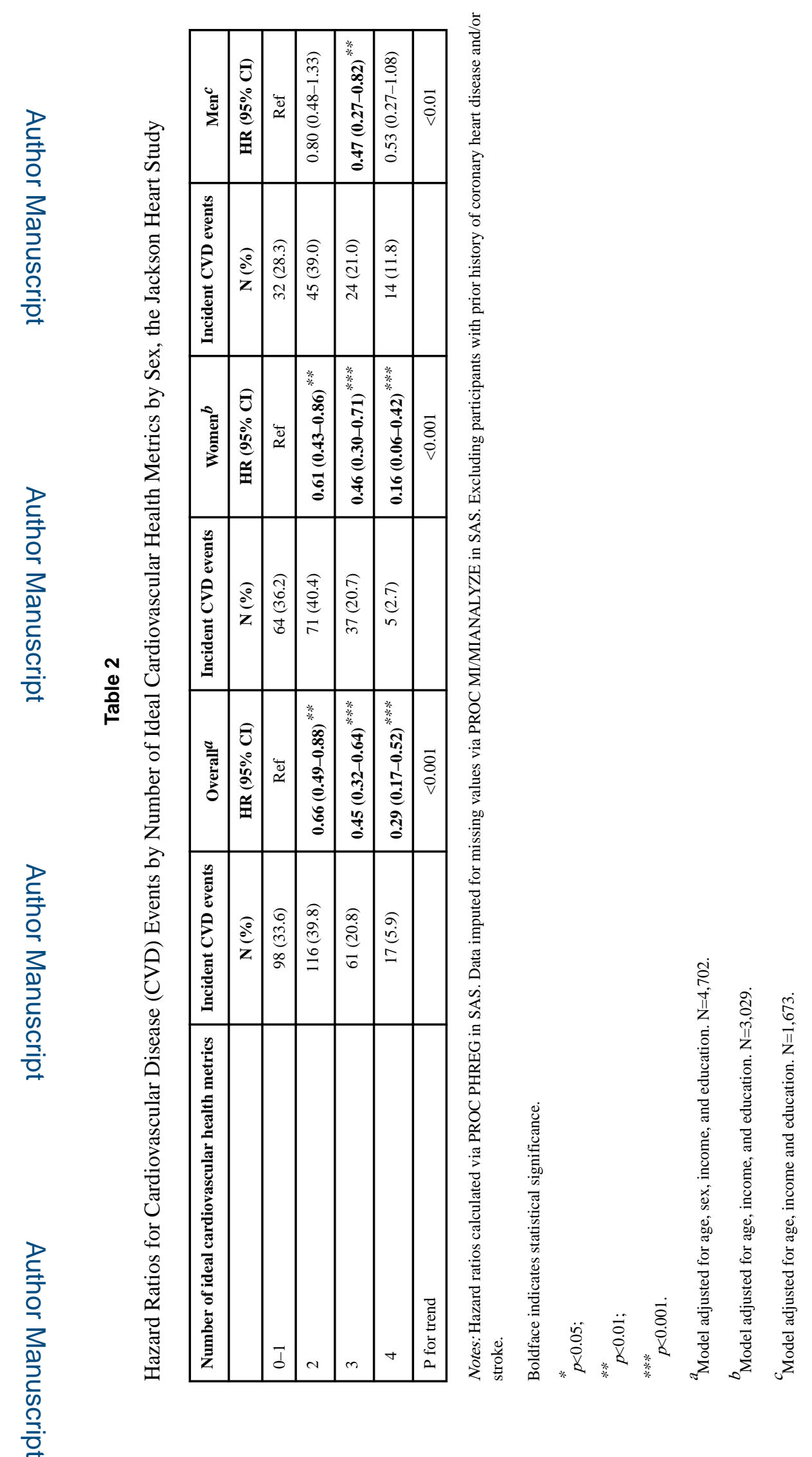

Am J Prev Med. Author manuscript; available in PMC 2017 October 01. 